\title{
Finite Element Modeling of RHS Splice Beam Bolted Connections
}

\author{
M. R. Mohamadi-Shoore ${ }^{1 *}$, H. Ghafari ${ }^{2}$ and M. Amankhani ${ }^{3}$ \\ 1,2Department of Civil Engineering, Islamic Azad University-Chalus, Iran \\ ${ }^{3}$ Department of Civil Engineering, Islamic Azad University-Tehran Southern, Iran \\ Mohammadi@iauc.ac.ir', Ghafari@iauc.ac.ir², manager@ab-ce.com³
}

\begin{abstract}
This paper describes a Finite Element Modeling (FEM) of splice beam connections using RHS subjected to pure bending. A three dimensional (3D) finite element model consist of an end-plate, four bolts, weld and the beam web is conducted by using the software package SUT-DAM. Particularly, contact interaction between surfaces is modeled. It is assumed that the elasto-plastic law is constitutive. The model includes both material and geometric nonlinear behavior. The result of existing experimental work is used to calibrate the model. This model clearly shows accurate correlation between FEM and experimental result.
\end{abstract}

Keywords: Moment End-plate Connection, Bolted Connection, Rectangular Hollow Section, Finite Element Modeling.

\section{Introduction}

The study and use of moment resisting end-plates connections both beam-to-beam splices and beamto-column connections return to the 1960s. The end-plate connections are very economical for several reasons. Erection of steel structures becomes simple due to using end-plate connection because shop welded and field bolted are required and construction time will be reduced. Also, proper and accurate fabrication and design techniques of moment end-plates make them more economically feasible for use in multi-story buildings.

A plate which is shop welded to the end of a beam and then field bolted to the connecting member utilizing high strength bolts, forms an end-plate moment connection. This connection is used to build a connection of beam to column or to join two beams together. By changing in connection parts, variable connections are designed. These changes are for instance in number of connection bolts, angle of connection axis, and section of

\footnotetext{
* Corresponding author:
}

M. R. Mohamadi-Shoore (Mohammadi@iauc.ac.ir) the beam. Each of the mentioned changes causes noticeable changes in the behaviour of the connection. Special type of end-plate connections utilize RHS as the web which are increasingly being used in main structures. Figure 1 depicts a typical shape of the moment end-plate connection using RHS. Widely, moment end- plate connection joining I-section members are used and there are several studies discovering the behaviour of this type of connections. Krishnamurthy et al. [1] also Patel and Chen [2] employed two dimensional models of finite element analysis. Krishnamurthy and Graddy [3] carried out for verification with some 3D analysis. Because of improving the computer packages, an increasing 3D finite element analysis of connections was conducted $[4,5,6]$. Different types of finite-element analysis packages were used for connection analysis. Thambiratnam and Krishnamurthy [4] used a special package for bolted connections. Patel and Chen [7] used a general nonlinear structural analysis program. Bursi and Leonelli [8] and Bursi and Jaspart [6] used the ABAQUS finite-element 
package. Most of the previous authors studied the endplate connections subjected to flexural loads. Again, Bursi and Jaspart [6] highlight the importance of correct element selection to obtain accurate solutions, and have endeavoured to establish benchmarks that can be used to calibrate finite-element models. They also showed that realistic modeling of bolted end-plate connections is highly complex because the problems are $3 \mathrm{D}$ in nature and involve the added complications of geometric and material nonlinearities, as well as contact/separation between various components [6].

By contrast, end plate connections joining RHS are investigated limitedly. Some researchers initiated the use of RHS in columns only and carried out the experimental and analytical investigations on connections between I-beam and box-column sections. White and Fang [9] carried out experimental investigations on the behaviour and performance of different types of I-beam to box-column top and seat angle connections, using a combination of welding and bolting. Wilkinson [10] develops appropriate design rules for cold-formed RHS for use in the limit states steel design. The best was done by Wheeler et al. [11] reported test results and analysis of connections between RHS using an end plate and pretension bolts. The connections failed by tensile bolt fracture or excessive deformation of the end plate. The objective of this paper is to perform an accurate FEM of splice beam connection using RHS in order to overcome the weakness of experimental tests known as a costly method of investigation.

\section{Finite Element Modeling (FEM)}

Finite element method is a reliable way for investigating the effect of all relevant parameters in simulating all complex cases and can model a large number of variables. The results of this method are acceptable and accurate because it includes all the complex phenomena occurring between each connection element such as contact, friction, stick and slip conditions. In this section a 3D finite element model is described to establish the behaviour of beam splice connection type shown in Figure 1.

\subsection{Model Description}

For modeling, SUT- DAM which is a nonlinear finite element program developed at Sharif University of

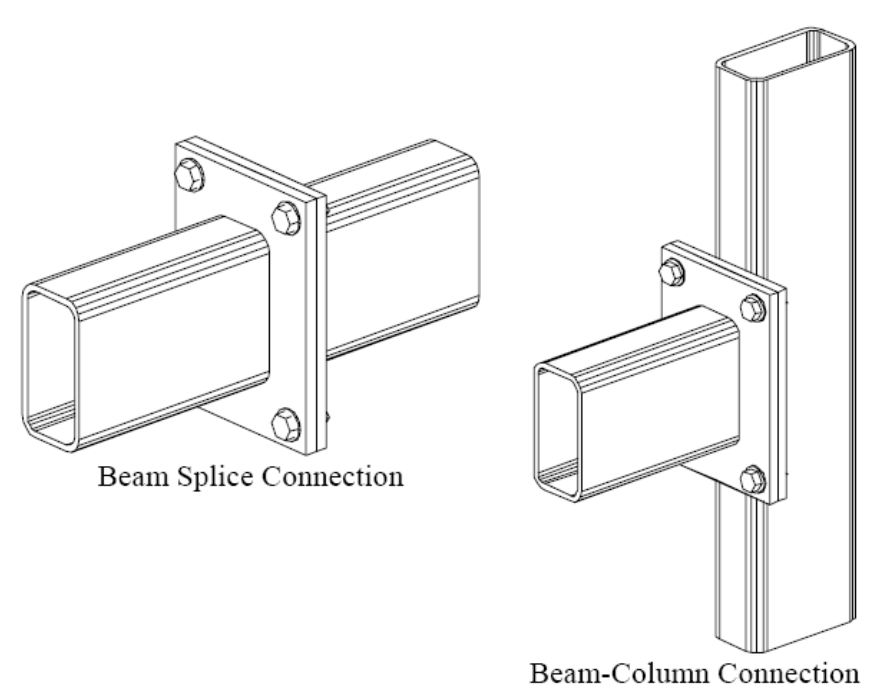

Figure 1. Examples of bolted moment end-plate connection using RHS.

Technology is using. A 3D nonlinear finite element model of the connection lying on a suitable mesh arrangement is generated. Achieving this aim, several numbers of different trial models were created. At first, models with different shell and solid type elements were experimented. In order to have an accurate stress distribution and reasonable analysis time, a suitable mesh configuration is needed then a fine mesh in areas of high stress and a mesh consist of large particles in the remaining areas are used. Also several numbers of bolts head modeling with sell elements and solid elements were tried. In addition bolts shank were modeled by solid elements and link elements.

Because of the plane of symmetry existing along the section through the beam web, in the final finite element model only one-half of the beam and end plate was modeled. Therefore, for the nodes on the mid-thickness of beam webs and mid-width of end plate symmetric displacement boundary conditions can be defined. After a large number of try and error, the mesh size in the middle of end-plate length and the beam web depth were taken as large as possible then the models size and analysis time were reduced. Conversely, near the bolt head and beam flanges the mesh size is small enough to make the accuracy of analysis results in the critical regions possible. In the $3 \mathrm{D}$ model, brick element which is 20-noded hexahedral solid isoparametric element was used to model the beam, end plate, bolt head and bolt shank. Brick elements have three translational degrees 
of freedom per node and are numerically integrated i.e. full integration, 14 Gauss points. These elements are capable of creating suitable model of curved regions. Through the different thickness of connection components, different set of elements makes acceptable results. Five set of elements for end plate, five set of elements for bolts head, two set of elements for beam flange and three set of elements for beam web through their thickness makes accurate simulate of the flexural behaviour of components. The surface-to-surface contact and target elements are used to model the interactions between the surfaces of the end- plates. The sliding and sticking conditions are presented with the classic isotropic Coulomb friction law with the coefficient equal to 0.3 . Tightening of bolts causes pretension effects in them which initially were shown by Abolmaali et al. [12] Feng et al. [13] and Al-Jabria et al. [14]. It is presented by connection elements which makes a connection between two imaginary parts of the bolt shank.

\subsection{Boundary and Load Conditions}

The center of bolts at the middle of the bolts shank is restrained then the displacement in $\mathrm{X}$; $\mathrm{Y}$ and $\mathrm{Z}$ direction is zero. Also the $\mathrm{Y}$ direction of the underside of the end plate is restrained in order to removing the shear force from the bolts. Loading was applied in two steps. In the first loading step, bolt pre-loading is done. In the second loading step, the loads causing bending moment at the connection were applied incrementally. For simplicity, loading was tension and compression load on the cantilever beam end. Within each increment, the equilibrium equations are based on the full Newton-Raphson iteration method. A quadratic convergence is achieved within each increment.

\subsection{Material Properties}

A typical stress-strain relation used in this work is depicted in Figure 2. The stress-strain relationship for the elements of the end plate, beam web and bangs is supposed like the elastic-strain hardening of S350. Young's modulus and Poisson's ratio for the elastic part of the stress-strain curve of the steel according to BS 5950; are respectively equal to $210 \mathrm{GPa}$ and 0.3 . At the yield point of beam and end-plate steel, the tangential stiffness is defined as $4 \%$ of the initial modulus of elasticity up to $8 \mathrm{e}_{\mathrm{y}}$ which increases to its related ultimate

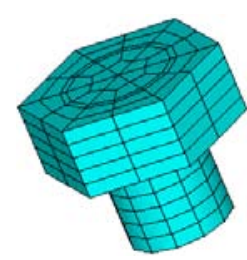

Figure 2. Hex head bolt layout.

stress at $20 \mathrm{e}_{\mathrm{y}}$. For the bolt material, both shank and head, it is assumed that $\mathrm{e}_{\mathrm{p}}=3 \mathrm{e}_{\mathrm{y}}$ and also $\mathrm{e}_{\mathrm{u}}=8 \mathrm{e}_{\mathrm{y}}$; finally at flat line, the strain $\mathrm{e}_{\mathrm{u} 2}=1.05 \mathrm{e}_{\mathrm{u}}$ is considered. For the all parts material, the Von- Mises yield criterion is adopted in order to obtain the reaction of model in the inelastic regions. Finally, in this type of connection because of grate geometrical nonlinearity, large displacement and large strain features are assumed.

\section{Calibration of Model with Experimental Tests}

First, the experimental program reported by Wheeler [11] which conducted on beam-to-beam connections was used for comparison with the delivered 3D FEM results. The moment-rotation behaviour of the connections tested experimentally and described. This study was dealt with the connection containing four bolts as shown in Figure 3. The connection was tested in pure bending by subjecting a beam, containing a beam splice connection at mid span [11] (Figure 1).The geometrical parameters of the specimens used in experimental test are the plate size (WP, Dp) and the plate thickness (tp). The specimen contains one row of bolts above and other below the section. Parameter (ae) shows the distance from the edge of the plate to the center of bolts. For M20 bolts, all holes have a diameter of $22 \mathrm{~mm}$. The beam section is RHS shape and the distance between bolts center and the section flange and also section web are defined as (So) and (c) respectively. The end-plate material was 350 grade steel i.e. the static yield stress (fy) and the ultimate tensile strength (fu) for the end plate are 350 and $499 \mathrm{MPa}$. The section was manufactured with a nominal yield stress of $350 \mathrm{MPa}$ too. Wheeler et. al [11] presented several experimental results in which the parameters mentioned above varied. Parameter (ae) was constant for all tests and set at $30 \mathrm{~mm}$. The bolts were M20 structural grade 8.8. This weld was qualified to AS 1554.1 with a nominal leg length of $8 \mathrm{~mm}$ for the 


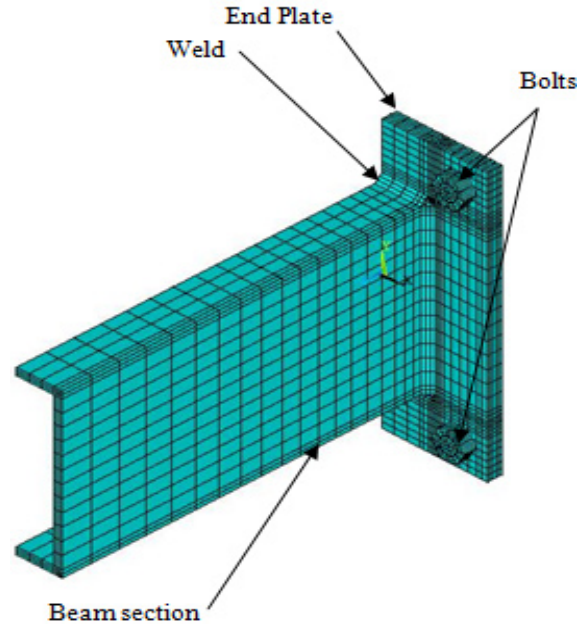

Figure 3. (3D) Finite element model.

fillet. In order to remove the effect of local buckling within the beam section, the used section is compact. The ultimate load of the specimen was limited to connection failure.

\subsection{Geometry of Tests}

Two specimens of experimental tests are considered. The geometrical characteristics of the specimens discussed in this paper are shown in Tables 1 and 2.
Table 1. End-plate connection details

\begin{tabular}{lcccccc}
\hline Specimen no. & Section type & \multicolumn{5}{c}{ Plate Dimensions $(\mathrm{mm})$} \\
\hline & & $\mathrm{t}_{\mathrm{p}}$ & $\mathrm{W}_{\mathrm{p}}$ & $\mathrm{D}_{\mathrm{p}}$ & $\mathrm{S}_{\mathrm{o}}$ & $\mathrm{c}$ \\
1 & $\mathrm{SHS}$ & 16 & 210 & 280 & 35 & 0 \\
2 & RHS & 16 & 230 & 330 & 35 & 35 \\
\hline
\end{tabular}

Table 2. Nominal section details

\begin{tabular}{lccc}
\hline Section & Depth $\mathrm{d}(\mathrm{mm})$ & Width $\mathrm{b}(\mathrm{mm})$ & Thickness $_{\mathrm{s}}(\mathrm{mm})$ \\
\hline SHS & 150 & 150 & 9 \\
RHS & 200 & 100 & 9 \\
\hline
\end{tabular}

\subsection{Numerical IIlustrations}

In order to evaluate the reliability of the delivered $3 \mathrm{D}$ FEM, the moment-rotation curves obtained from experimental results and FEM studies are used for direct comparison. Through depicted curves, a good agreement between the numerical and experimental results can be seen. Therefore, it is concluded that all the main features of the behaviour of the connections can be accurately represented by the proposed 3D FEM. For instance, the ultimate moment obtained from 3D FEM $\left(\mathrm{M}_{\mathrm{uf}}\right)$ are compared with the experimental ultimate moment $\left(\mathrm{M}_{\mathrm{uw}}\right)$ for both specimens. As shown in Table 3, the experimental
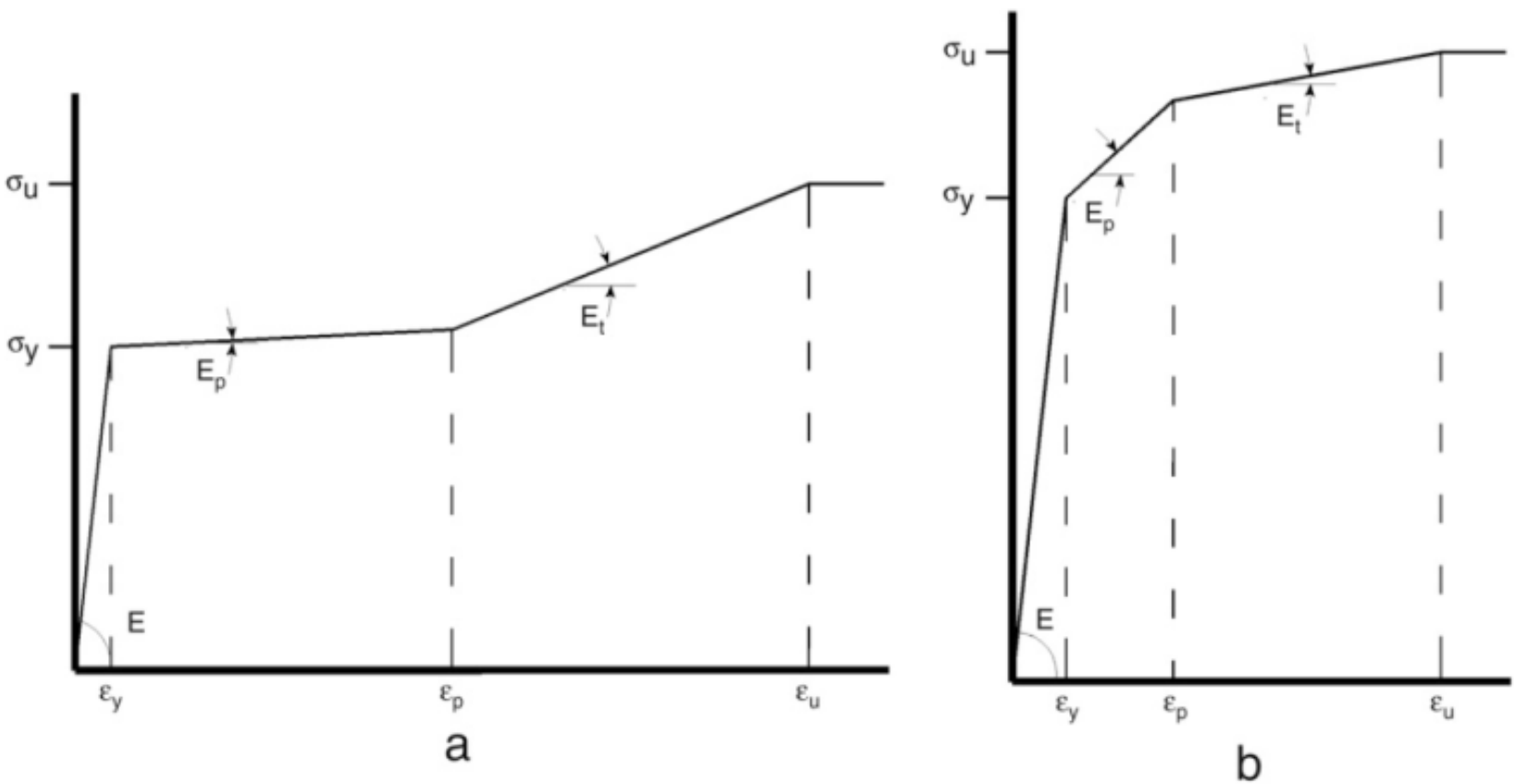

Figure 4. Idealized material behaviors used in the FEM analysis for: (a) End plate and beam (b) High-strength bolts. 
Table 3. Nominal section details

\begin{tabular}{lccc}
\hline Specimen no. & Experimental $\mathrm{M}_{\mathrm{uw}}(\mathrm{KN} . \mathrm{m})$ & SUT-DAM M $_{\mathrm{uf}}(\mathrm{KN} . \mathrm{m})$ & $\mathrm{M}_{\mathrm{uf}} / \mathrm{M}_{\mathrm{uw}}$ \\
\hline 1 & 65.34 & 62 & 0.95 \\
2 & 69.81 & 72 & 1.03 \\
\hline
\end{tabular}

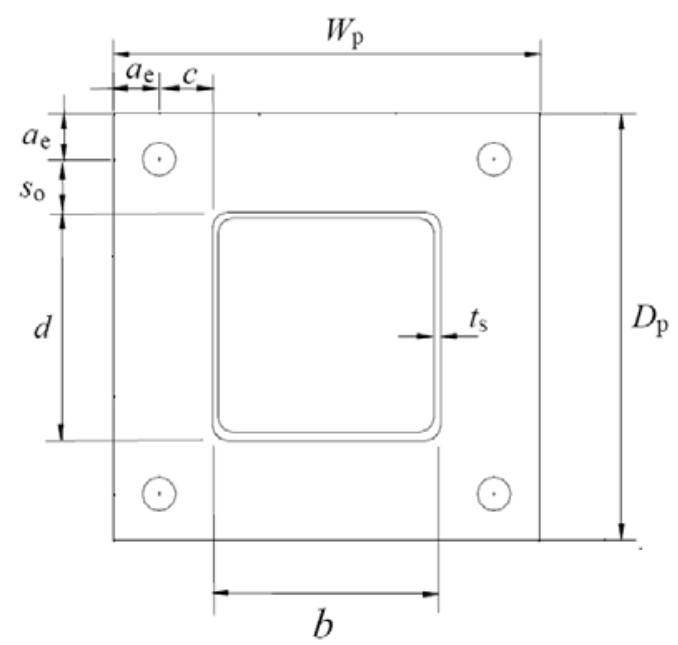

Figure 5. General end-plate layout.

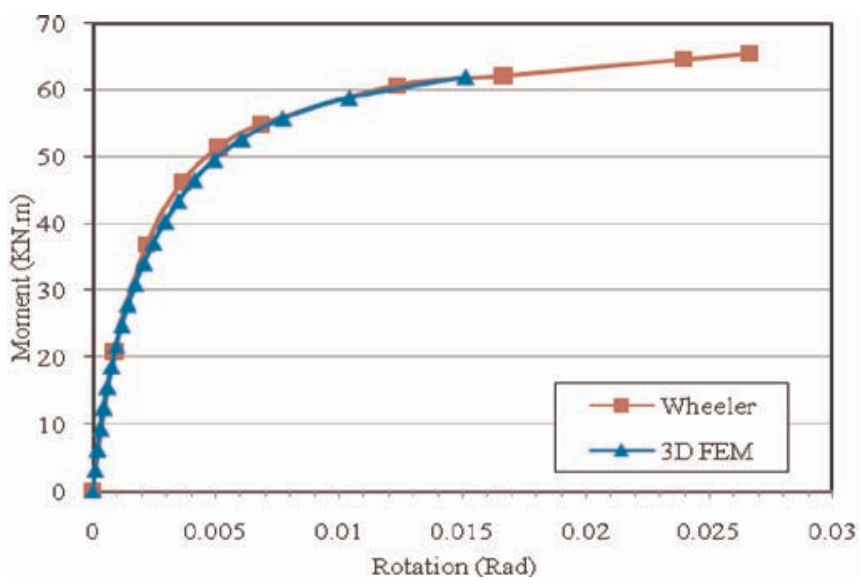

Figure 6. Comparison between 3D FEM result and Wheeler's result (specimen no.1).

ultimate moment and the numerical ultimate moment, correspond with together very well.

\section{Summary and Conclusion}

A numerical investigation is presented in this paper to provide a satisfactory model of the behaviour of splice beam connection using RHS by a complete 3D finite element model. The modeling was conducted using SUT-

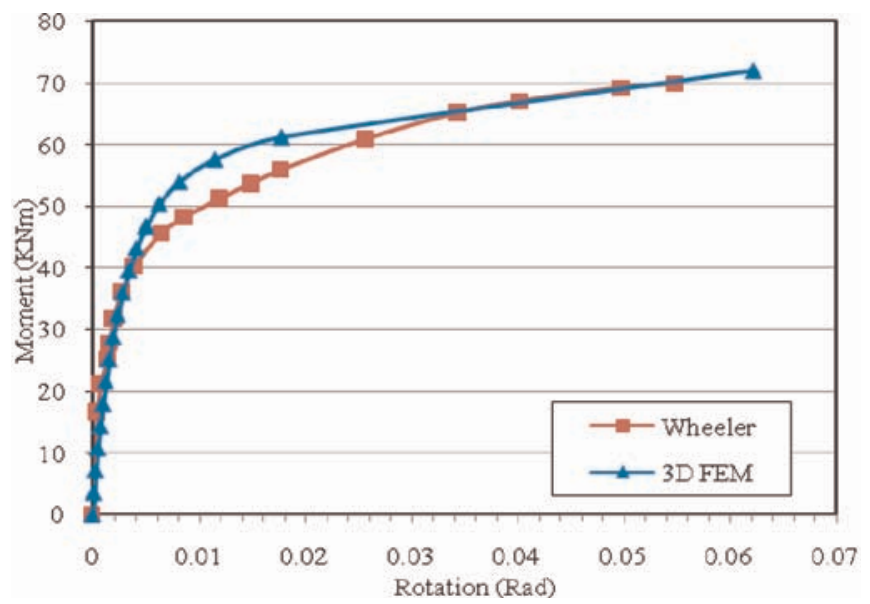

Figure 7. Comparison between 3D FEM result and Wheeler's result (specimen no.2).

DAM software package. The 3D finite element model uses 20-noded hexahedral solid elements because this type of element can be adapted to all critical regions. The model is calibrated with two experimental tests which differ in some geometrical parameters. A good agreement between the numerical and experimental results is seen.

Finally, it is known that the moment- rotation curve expresses the main structural properties. Because of the accuracy of the mentioned FEM, the properties of splice beam end-plate connections such as moment resistance, rotational stiffness both initial and plastic stiffness and also rotation capacity can be acquired of the moment-rotation curve presented by FEM easily.

\section{Acknowledgements}

The authors of this manuscript would like to appreciate for financial support of Deputy Research Center of the Islamic Azad University-Chalus branch.

\section{References}

1. Krishnamurthy N, Huang H T et al. (1979). Analytical M- $\Theta$ curves for endplate connections, Journal of the Structural Division ASCE, vol 105(1),133-145.

2. Patel K V, and Chen W F (1984). Non-linear analysis of steel moment connections, Journal of Structural Engineering ASCE, vol 110(8), 1861-1874.

3. Krishnamurthy N, and Graddy D E (1976). Correlation between 2- and 3-dimentional finite element analyses of steel bolted endplate connections, Computers \& Structures, vol 6(4-5), 381-389. 
4. Thambiratnam D P, and Krishnamurthy N (1989). Computer analysis of column base plates, Computer \& and Structures, vol 33(3), 839-850.

5. Bursi O S, and Jaspart J P (1997a). Benchmarks for finite element modeling of bolted steel connections, Journal of Constructional Steel Research, vol 43(1), 17-42.

6. Bursi O S and Jaspart J P (1997b) Calibration of a finite element model for isolated bolted end plate steel connections, Journal of Constructional Steel Research, vol 44(3), 225-262.

7. Patel K V, and Chen W F (1984). Non-linear analysis of steel moment connections, Journal of Structural Engineering, ASCE, vol 110(8) 1861-1874.

8. Bursi O S, and Leonelli L (1994). A finite element model for the rotational behaviour of end plate steel connections, Annual Technical Session, Structural Stability Research Council, Bethlehem, PA.

9. White R N, and Fang P J (1966). Framing connections for square structural tubing, Journal of the Structural Division, ASCE, vol 92(2),175-94.
10. Wilkinson T (1999). The plastic behaviour of coldform rectangular hollow sections, Thesis Presented for the Degree of Doctor of Philosophy, Department of Civil Engineering, The University of Sydney, Sydney, Australia.

11. Wheeler A T, Clarke M J et al. (1997). Bending tests of bolted end plate connections in cold-formed rectangular hollow sections, Res. Rep. No.R736, Dept. of Civil Engineering, University of Sydney, Australia.

12. Abolmaali A, Matthysa J H et al. (2005). Development of moment-rotation model equations for flush endplate connections, Journal of Constructional Steel Research, vol 61(1), 1595-1612.

13. Feng F, Lam D, and Ye J (2007). Parametric study of semi-rigid composite connections with 3-D finite element approach, Engineering Structures, vol 29, 888-898.

14. Al-Jabria K S, Seibib A et al. (2006). Modelling of unstiffened flush endplate bolted connections in fire, Journal of Constructional Steel Research, vol 62(1-2), 151-159. 